\title{
The relationship between internal pay gap and performance of listed companies in high-tech industry
}

\author{
Jin di Yang ${ }^{1, a}$, Tong $\mathrm{Xie}^{2, \mathrm{~b}}$, and Hong ping Lian ${ }^{3, \mathrm{c},{ }^{*}}$ \\ ${ }^{1,3}$ Beijing Normal University, School of Government, Beijing China \\ ${ }^{2}$ Beijing Normal University, Faculty of psychology, Beijing China \\ a201821260024@mail.bnu.edu.cn, b201821061100@mail.bnu.edu.cn, chplian@bnu.edu.cn
}

Keywords: high-tech industry, pay gap, enterprise performance, property right.

\begin{abstract}
Based on the contingency theory, this study takes 380 listed companies in high-tech industry as the research object and explores the impact of internal pay gap on corporate performance. At the same time, this paper also studies the effect of the nature of corporate property rights on the relationship between internal pay gap and corporate performance. The research results show that the internal pay gap of high-tech enterprises has an inverted U-shaped relationship with enterprise performance, that is, as the internal pay gap increases, it is beneficial to the performance of the enterprises within a certain range. If it exceeds a certain range, the increase of internal pay gap will negatively affect the performance of enterprises. The nature of property rights of enterprises has a regulating effect in the impact of pay gaps on corporate performance. Compared with private enterprises, state-owned enterprises are more suitable for relatively small pay gaps.
\end{abstract}

\section{Introduction}

With the official implementation of the Reform Plan for the salary System of Central Management Personnel in Enterprises in 2015, the pay gap and salary reform have gradually become a hot spot of social concern. Regarding the research on the internal pay gap of enterprises, most of the existing literatures analyze the same year's pay gap, and ignore the time it takes for the pay gap to impact the performance of the enterprises. Compared with Western countries, under the background of public ownership in China, state-owned enterprises are greatly influenced by traditional egalitarianism. Therefore, integrating the nature of the property right into relevant research is more pertinent to guide the practice of Chinese enterprises. This study selects 380 listed companies in high-tech industry as research objects, employs the 2011-2016 data to establish a panel data model for empirical research, and uses the nature of corporate property right as a moderator to explore the relationship between the internal pay gap and the next year's corporate performance. This study has great significance to the establishment of the company's salary system.

\section{Theoretical basis}

At present, the existing theories about executive-general employee pay gaps mainly include behavior theory and tournament theory. Behavior theory believes that reducing the internal pay gap is beneficial to performance. The tournament theory advocates increasing the pay gap, and thereby work efficiency will also be increased. In addition, there are researches to support the theory of contingency, that is, there's an inverted U-shaped relationship between pay gap and corporate performance. Beyond a certain range, the impact of the increase in the pay gap on corporate performance will change from a promoting role to a damaging effect.

\subsection{Behavior theory}

Behavior theory includes four theoretical branches---distribution preference theory, social comparison theory, relative exploitation theory and organizational politics theory. It states that the pay gap will directly affect individual performance and in turn affect corporate performance, and believes that internal pay gap will reduce employees' enthusiasm that will reduce the business 
performance. Levine conducted an empirical study on listed companies and the results showed that the excessive pay gap undermines employee job satisfaction and reduces their enthusiasm and work efficiency. This study supports behavior theory from the perspective of social comparative theory ${ }^{[1]}$. Milgrom's research explained that when the pay gap is too large, employees tend to pay too much attention to their own performance, ignoring teamwork and collaboration, and individual performance deviates from the collective team performance. This study supports the hypothesis of behavioral theory from the perspective of organizational politics theory ${ }^{[2]}$. YL Tao et al. conducted an empirical study on the Major League Baseball in the United States and found that increasing the gap of salary and bonus has a negative impact on team performance ${ }^{[3]}$. Zhang Zheng tang's research showed that reducing the internal pay gap can improve employees' enthusiasm for work, and thereby improve the performance of the company ${ }^{[4]}$. Liu Ye et al. found that the impact of the pay gap on performance needs time to demonstrate, and reducing the pay gap is conducive to the company's next performance ${ }^{[5]}$. Liao Yi demonstrated the enthusiasm and production efficiency of manufacturing industry's employees is significantly reduced when the internal pay gap is too large ${ }^{[6]}$.

\subsection{Tournament theory}

Lazear and Rosen proposed the tournament theory in 1981. They thought that the work and development in the enterprise can be regarded as a tournament. Promotion and salary increase are the rewards of the tournament. The greater pay gap means the greater reward for winning the competition. The greater pay gap can enhance the motivation of the contestants and improve their enthusiasm for work, and the company's performance will be improved accordingly ${ }^{[7]}$. Harder used professional basketball team and baseball team as the research object, and proved that the greater difference in bonuses of sports events, the more able the team is to stimulate the training efficiency and performance of athletes ${ }^{[8]}$. Milkovich and Newman's research showed that a small pay gap will make talents feel that their work efficiency and high performance are not fully recognized and compensated, resulting in dissatisfaction, and thus reduce business performance ${ }^{[9]}$. Kale found that the wide internal pay gap of listed companies in the United States can improve the enthusiasm of managers and executives, which plays an important role in achieving high-efficiency output, which means that a large salary gap can improve the overall performance of the company ${ }^{[10]}$. Zhang Ming et al. conducted empirical research on listed companies and made a distinction about the growth of the company, indicating that regardless of the growth of the company, the internal pay gap has a positive effect on the company performance, further refining the tournament theory ${ }^{[11]}$. Based on the perspective of traditional culture's influence on the perception of fairness, Yang Jing zhao believed that under the influence of modern market economy development and Western culture, most Chinese employees can adapt to the large pay gap at this stage, demonstrating the applicability of the tournament theory in China ${ }^{[12]}$. Cao Hui conducted a deeper discussion on the impact of the pay gap, indicating that the pay gap actually has different effects on executives and employees, but overall the executive-employee pay gap is positively related to corporate performance. Which is consistent with the tournament theory ${ }^{[13]}$.

\subsection{Contingency theory}

The contingency theory holds that both the behavior theory and the tournament theory have certain applicable ranges. Both theories can only explain the impact of the pay gap on the enterprise's performance to a certain extent. The pay gap and the performance of enterprises has an inverted Ushaped relationship. Bingley and Eriksson used Danish listed companies as research objects and regarded human capital as a moderator. The results showed that there was an has an inverted U-shaped relationship between the pay gap and corporate performance among white-collar workers with higher ranks ${ }^{[14]}$. Y Dai's research verified that there is an inverted U-shaped relationship between internal pay gaps and employee productivity ${ }^{[15]}$. Li Wenjing et al. carried out a more detailed analysis of the applicable range of the behavior theory and the tournament theory. The results showed that the tournament theory mainly plays a role when the pay gap is small, and behavior theory, especially social comparison theory, can explain the pay gap when the pay gap is large ${ }^{[16]}$. Gao Liang mou et al. found that in the companies of different property rights and in different regions, the pay gap changes 
from a promoting role to a damaging effect on the corporate performance ${ }^{[17]}$.

\section{Research hypothesis}

Behavior theory holds that small salary gap can improve the sense of fairness perceived by ordinary employees at work, and can also promote cooperation among team members, which is conducive to the improvement of corporate performance. Excessive pay gap leads employees to pay too much attention to their performance and ignore cooperation with other members. Tournament theory believes that the greater the pay gap, the higher the effectiveness of promotion, the more motivated employees, which can improve the performance of the entire company. At the same time, the larger pay gap is more likely to attract high-capacity managers and reduce management costs. On the other hand, the small pay gap makes high-efficiency and high-capacity managers feel that their work has not received the recognition and compensation they deserve. Which creates slack in the work and is not conducive to the improvement of company performance. The contingency theory believes that the relationship between internal pay gap and firm performance is not linear, both behavior theory and tournament theory have their application scope, that is the pay gap can improve performance within a certain range, but excessive pay gap will impair performance. There exists an inverted Ushaped relationship between pay gap and corporate performance.

As a special industry, high-tech industry has relatively high requirements for the overall quality and technical ability of general employees, at the same time, the research and development process emphasize cooperation, this actually requires that the pay gap of high-tech industry is smaller than other industries. On the other hand, high-tech industries are knowledge-intensive industries, the competition for talents is fierce and requires high-efficiency management. Which makes high-tech industry more suitable for larger pay gaps.

In short, the relationship between pay gap and corporate performance in high-tech industry is more complicated and sensitive. Based on this, the study proposes the following hypothesis.

$\mathrm{H}_{1}$ : In the high-tech industry, there is an inverted U-shaped relationship between the executiveemployee pay gap and corporate performance.

Based on the actual controller, this study divides listed companies into state-owned enterprises and private enterprises. State-owned enterprises can provide political benefits and social status, the salary has limited incentives for state-owned enterprise executives. In addition, compared with private enterprises, the traditional fair distribution culture has deeper impact on state-owned enterprises. Therefore, employees of state-owned enterprises are more sensitive to internal pay gaps. Excessive pay gap is extremely negative for employees' sense of fairness and enthusiasm for work, which in turn reduces business performance.

Relatively speaking, private listed companies tend to have a rather good competitive atmosphere, performance appraisal is more standardized, executives' promotion system are more market-oriented, and salary has stronger incentives for executives.

The empirical research supporting the contingency theory has further refined research on the moderation effect of the nature of property rights, and found that the nature of property right of the company does have a moderating effect on the relationship between pay gap and corporate performance. Bai Pei wen distinguished enterprises with different property rights and the results showed that under different property rights, the impact of pay gap on corporate performance is not the same ${ }^{[18]}$. Shi Liu hong et al. have found that the overall pay gap and performance show an inverted U- shaped relationship, and the nature of property right has an impact on the relationship. The performance of state-owned enterprises is more sensitive about the internal pay gap ${ }^{[19]}$.

Based on this, this study suggests that smaller pay gap is more conducive to the performance of state-owned enterprises, while private enterprises are suitable for a relatively large pay gap, and put forward the following hypothesis.

$\mathrm{H}_{2}$ : In the high-tech industry, the turning point of the inverted U-shaped curve reflecting the relationship between internal pay gap and corporate performance of state-owned enterprises precedes that of private enterprises. 


\section{Empirical Research}

\subsection{Data Collection and Selection}

The definition and selection of high-tech companies in this study are mainly based on the High-tech Industry Statistical Yearbook 2016 and the High-tech Industry (Manufacturing) Classification (2013) issued by the National Bureau of Statistics. Based on the Wind database, Guo Tai an database and the listed company's annual report, 380 high-tech industry listed companies in Shanghai and Shenzhen stocks from 2011 to 2016 were selected, and 1917 valid samples were finally obtained.

\subsection{Variable description}

\subsubsection{Independent variable}

First of all, based on the regulations of the China Securities Regulatory Commission, this research defines the senior management team as including senior management personnel and members of the board of directors and supervisors.

Secondly, although listed companies have gradually begun to implement the equity incentive system in recent years, the current executives still hold few shares, and the system is still not mature in China. In addition, on-the-job compensation as a kind of implicit salary is not clearly reflected in the annual report, and it is difficult to distinguish between the on-the-job compensation enjoyed by senior executives and general employees. Therefore, this study defines salary as the monetary compensation of executives and general employees, and does not include long-term salary such as on-the-job consumption and stock options.

In addition, according to Lin Jun qing et al.'s research ${ }^{[20]}$, the internal pay gap in this study is defined as the difference between the average annual salary of the senior management team and the average annual salary of the general staff. The absolute salary gap (MEGAP 1 ) and the relative salary gap $\left(\mathrm{MEGAP}_{2}\right)$ are used to measure the internal pay gap.

Table 1 Definition of the average annual salary within the enterprise

\begin{tabular}{|c|l|}
\hline Name & \multicolumn{1}{c|}{ Definition } \\
\hline $\begin{array}{c}\text { The average annual } \\
\text { salary of the senior } \\
\text { management team }\end{array}$ & $\begin{array}{l}\text { Salary of all directors, supervisors and other senior management personnel of the company/ } \\
\text { Total number of directors, supervisors and senior management personnel receiving salary }\end{array}$ \\
\hline $\begin{array}{c}\text { The average annual } \\
\text { salary of the general } \\
\text { staff }\end{array}$ & $\begin{array}{l}\text { [ (Total cash paid to employees and paid for employees in the current year + Total wages } \\
\text { payable at the end of the year - Total wages payable at the beginning of the year) - Total } \\
\text { executive team salary]/ ( Total number of employees -Total number of the senior } \\
\text { management team) }\end{array}$ \\
\hline
\end{tabular}

\subsubsection{Dependent variable}

In this study, the enterprise performance was measured by using the financial performance index --Return on total assets, which is used by domestic research and could accurately represent corporate performance.

\subsubsection{Moderator variables}

This study distinguishes the enterprise property rights (OWNERSHIP) by whether the actual controller is a natural person or a state-owned asset management department.

\subsubsection{Control variable}

\subsubsection{Region (AREA)}

Enterprises located in the eastern developed regions may enjoy more abundant resources, and the environment for economic development is better, and it is usually easy to achieve better performance. The performance of companies in underdeveloped regions may be limited by the constraints of resources and economic systems. According to the different levels of economic development, this study distinguishes all samples according to whether they are located in eastern developed regions or underdeveloped regions.

According to the marginal production effect, the increase of the company's scale can reduce the 
transaction cost, and to some extent, the incentive effect of the manager on the enterprise 's performance improvement is more significant. On the other hand, the size of the company being too large will inevitably increase operational pressure, which is not conducive to the improvement of performance. Therefore, this study controls the possible impact of firm size on firm performance.

\subsubsection{Asset-liability ratio (DEBT)}

Compared with equity financing, if company adopts a financing method with a high debt ratio, it can reduce costs and improve corporate performance.

\subsubsection{Company's listing period ( $A G E$ )}

Under normal circumstances, the longer the listing period, the more mature the company's system and the more complete the management, which will help the company's stability and performance.

\subsubsection{Past corporate performance (FROA)}

The company performance in the previous year and the various external factors that form the performance will have an impact on the company's performance in the next year. This study uses the company's ROA in the previous year to represent the company performance in the previous year, and controls the impact of this variable by adding it into the equation.

Table 2 Variable definition table

\begin{tabular}{|c|c|c|c|}
\hline Variable type & Variable name & Variable symbol & Variable definition \\
\hline \multirow[t]{2}{*}{ Dependent variable } & $\begin{array}{l}\text { return on total } \\
\text { assets }\end{array}$ & ROA & net profit / average total assets $* 100 \%$ \\
\hline & $\begin{array}{l}\text { the absolute pay } \\
\text { gap }\end{array}$ & $M E G A P_{1}$ & $\begin{array}{l}\text { the natural logarithm of the difference between the average annual } \\
\text { salary of the senior management team and employee }\end{array}$ \\
\hline $\begin{array}{l}\text { Independent } \\
\text { variable }\end{array}$ & $\begin{array}{l}\text { the relative pay } \\
\text { gap }\end{array}$ & $M E G A P_{2}$ & $\begin{array}{l}\text { the average annual salary of the senior management team /the average } \\
\text { annual salary of the general staff }\end{array}$ \\
\hline \multirow[t]{3}{*}{$\begin{array}{l}\text { Adjustment } \\
\text { variables }\end{array}$} & $\begin{array}{l}\text { the nature of } \\
\text { enterprise property } \\
\text { right }\end{array}$ & OWNERSHIP & State-owned enterprise is 1 , otherwise 0 \\
\hline & region & AREA & $\begin{array}{l}\text { If the enterprise registration is located in the developed eastern region, } \\
\qquad A R E A=1 \text {, otherwise } 0\end{array}$ \\
\hline & company size & SIZE & The natural logarithm of the company's total assets \\
\hline \multirow[t]{3}{*}{ Control variable } & asset-liability ratio & DEBT & total liability / Total assets $* 100 \%$ \\
\hline & $\begin{array}{l}\text { company's listing } \\
\text { period }\end{array}$ & AGE & The period of the year minus the year of listing \\
\hline & $\begin{array}{l}\text { past corporate } \\
\text { performance }\end{array}$ & FROA & $\begin{array}{l}\text { net profit in the previous year / average total assets in the previous year } \\
\qquad * 100 \%\end{array}$ \\
\hline
\end{tabular}

\subsection{Research model}

This study intends to verify the relationship between the internal pay gap and the next year's corporate performance. The research model is as follows

$$
\begin{aligned}
& R O A=\beta_{1} M E G A P_{1}+\beta_{2} M E G A P_{1}^{2}+\beta_{3} A R E A+\beta_{4} S I Z E+\beta_{5} D E B T+\beta_{6} A G E+\beta_{7} F R O A+\varepsilon \\
& R O A=\beta_{1} M E G A P_{2}+\beta_{2} M E G A P_{2}^{2}+\beta_{3} A R E A+\beta_{4} S I Z E+\beta_{5} D E B T+\beta_{6} A G E+\beta_{7} F R O A+\varepsilon
\end{aligned}
$$

This study brings the first and quadratic terms of the absolute and relative pay gaps into the equation to explore and verify the inverted U-shaped relationship between the pay gap and the next year's performance, and uses OWENERSHIP as a grouping variable to verify the moderating effect of the property right. 


\subsection{Data analysis and results}

\subsubsection{Descriptive analysis}

Table 3 Descriptive analysis of each variable indicator

\begin{tabular}{c|c|c|c|c|c}
\hline \hline Variable & Number of samples & Mean & Std. Dev. & Min & Max \\
\hline ROA & 1917 & 0.0555 & 0.0556 & -0.120 & 0.232 \\
\hline MEGAP $_{1}$ & 1917 & 11.82 & 0.979 & 3.678 & 15.05 \\
\hline MEGAP 2 & 1917 & 9.779 & 2.910 & 1.000 & 30.96 \\
\hline OWNERSHIP & 1917 & 0.243 & 0.429 & 0 & 1 \\
\hline AREA & 1917 & 0.706 & 0.456 & 0 & 1 \\
\hline SIZE & 1917 & 0.215 & 0.00986 & 0.189 & 0.258 \\
\hline DEBT & 1917 & 0.328 & 0.196 & 0.0334 & 0.840 \\
\hline AGE & 1917 & 8.421 & 6.374 & 0 & 26 \\
\hline FROA & 1917 & 0.0620 & 0.0585 & -0.102 & 0.247 \\
\hline \hline
\end{tabular}

It can be seen that the average ROA of China's high-tech industry listed companies in 2011-2016 is 0.0555 , and the standard deviation is 0.0556 . So, companies in the sample have certain differentiation in business performance. The average absolute pay gap is 11.82 , and the average relative pay gap is 9.779. That is, the average annual salary of the senior management team is as 9.78 times as the average annual salary of the general employees, and there are certain differences within the sample companies. The OWNERSHIP mean is 0.243 , which indicates that $24.3 \%$ sample companies are state-owned enterprises. This ratio is lower than that of the entire A-share market. It can be seen that the proportion of private enterprises in listed high-tech industries in China is relatively high. The AREA mean is 0.706 , indicating that $70.6 \%$ listed companies in China's high-tech industries are located in the eastern developed region.

The distribution of variables is reasonable, there is no obvious extreme value, so the regression analysis can be performed.

\subsubsection{Correlation analysis}

Table 4 Correlation analysis between variables

\begin{tabular}{|c|c|c|c|c|c|c|c|c|c|}
\hline & ROA & $\overline{M E G A P_{1}}$ & 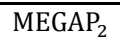 & OWNERSHIP & AREA & SIZE & DEBT & AGE & FROA \\
\hline ROA & 1 & & & & & & & & \\
\hline$M E G A P_{1}$ & 0.108 & 1 & & & & & & & \\
\hline MEGAP $_{2}$ & 0.0596 & 0.637 & 1 & & & & & & \\
\hline OWNERSHIP & -0.108 & 0.108 & 0.0444 & 1 & & & & & \\
\hline AREA & 0.0660 & 0.154 & 0.0459 & -0.0546 & 1 & & & & \\
\hline SIZE & -0.00610 & 0.445 & 0.370 & 0.321 & -0.0159 & 1 & & & \\
\hline DEBT & -0.319 & 0.105 & 0.130 & 0.289 & -0.0878 & 0.408 & 1 & & \\
\hline AGE & -0.160 & 0.143 & 0.167 & 0.482 & -0.139 & 0.444 & 0.500 & 1 & \\
\hline FROA & 0.736 & 0.129 & 0.0830 & -0.138 & 0.0832 & -0.0353 & -0.401 & -0.231 & 1 \\
\hline
\end{tabular}

It can be seen that the ROA is positively correlated with the absolute pay gap and the relative pay gap, but the influence of other control variables has not been considered, and further regression analysis should be conducted.

From the correlation coefficient among the variables, we know that the correlation is not high, 
which indicates that the information contained in the model has variation and the multicollinearity problem can be excluded.

\subsubsection{Regression analysis}

Table 5 Regression results of the pay gap's impact on the company performance

\begin{tabular}{|c|c|c|c|c|}
\hline \multirow{2}{*}{$\frac{\text { Variable index }}{\text { MEGAP }_{1}}$} & \multicolumn{2}{|c|}{ ROA } & \multicolumn{2}{|c|}{ ROA } \\
\hline & $\begin{array}{c}-0.00505 * * * \\
(0.00159)\end{array}$ & $\begin{array}{l}0.0169^{* *} \\
(0.00683)\end{array}$ & & \\
\hline $\mathrm{MEGAP}_{1}^{2}$ & & $\begin{array}{c}-0.00107 * * * \\
(0.000324)\end{array}$ & & \\
\hline$M E G A P_{2}$ & & & $\begin{array}{c}-0.00147 * * * \\
(0.000481)\end{array}$ & $\begin{array}{l}0.000187 \\
(0.00105)\end{array}$ \\
\hline $\mathrm{MEGAP}_{2}^{2}$ & & & & $\begin{array}{l}-7.50 \mathrm{e}-05^{*} \\
(4.20 \mathrm{e}-05)\end{array}$ \\
\hline SIZE & $\begin{array}{c}-1.114 * * * \\
(0.320)\end{array}$ & $\begin{array}{c}-1.047 * * * \\
(0.319)\end{array}$ & $\begin{array}{c}-1.166^{* * * *} \\
(0.317)\end{array}$ & $\begin{array}{c}-1.246^{* * *} \\
(0.320)\end{array}$ \\
\hline DEBT & $\begin{array}{c}0.0142 \\
(0.0105)\end{array}$ & $\begin{array}{c}0.0139 \\
(0.0104)\end{array}$ & $\begin{array}{c}0.0132 \\
(0.0105)\end{array}$ & $\begin{array}{c}0.0133 \\
(0.0105)\end{array}$ \\
\hline AGE & $\begin{array}{c}0.000540 \\
(0.000812)\end{array}$ & $\begin{array}{c}0.000754 \\
(0.000812)\end{array}$ & $\begin{array}{c}0.000136 \\
(0.000815)\end{array}$ & $\begin{array}{c}0.000278 \\
(0.000818)\end{array}$ \\
\hline FROA & $\begin{array}{c}0.146 * * * \\
(0.0253)\end{array}$ & $\begin{array}{c}0.153 * * * \\
(0.0254)\end{array}$ & $\begin{array}{c}0.143 * * * \\
(0.0253)\end{array}$ & $\begin{array}{c}0.140 * * * \\
(0.0253)\end{array}$ \\
\hline Constant & $\begin{array}{c}0.336 * * * \\
(0.0618)\end{array}$ & $\begin{array}{l}0.211 * * * \\
(0.0723)\end{array}$ & $\begin{array}{c}0.297 * * * \\
(0.0625)\end{array}$ & $\begin{array}{c}0.309 * * * \\
(0.0628)\end{array}$ \\
\hline Sample size & 1,917 & 1,917 & 1,917 & 1,917 \\
\hline$R^{2}$ & 0.050 & 0.057 & 0.050 & 0.052 \\
\hline Number of code & 471 & 471 & 471 & 471 \\
\hline
\end{tabular}

Note: Standard error in parentheses $* * * \mathrm{p}<0.01,{ }^{* *} \mathrm{p}<0.05, * \mathrm{p}<0.1$

It can be seen that after controlling other control variables, the first term coefficient of the absolute pay gap and the relative pay gap are negative, and passing the significance test at the $1 \%$ level, which shows that increasing pay gap between high managers and employees reduces business performance.

After adding the quadratic term, the quadratic term coefficient of the absolute pay gap and the relative pay gap are both negative, and the significance test is passed at the $1 \%$ and $10 \%$ level respectively. This shows that in the high-tech industry listed companies in China, the relationship of the pay gap between executives and general employees and the company's performance is inverted U-shaped, verifying the hypothesis $\mathrm{H}_{1}$.

Table 6 The Relationship between enterprise pay gap and performance under the influence of property right

\begin{tabular}{|c|c|c|c|c|}
\hline \multirow[t]{2}{*}{ Variable index } & $\begin{array}{l}\text { State-owned } \\
\text { enterprise }\end{array}$ & Private Enterprise & $\begin{array}{l}\text { State-owned } \\
\text { enterprise }\end{array}$ & Private Enterprise \\
\hline & \multicolumn{2}{|c|}{ ROA } & \multicolumn{2}{|c|}{ ROA } \\
\hline $\mathrm{MEGAP}_{1}$ & $\begin{array}{c}0.0226 \\
(0.0145)\end{array}$ & $\begin{array}{l}0.0159 * * \\
(0.00787)\end{array}$ & & \\
\hline $\mathrm{MEGAP}_{1}^{2}$ & $\begin{array}{l}-0.00135^{*} \\
(0.000745)\end{array}$ & $\begin{array}{c}-0.00107 * * * \\
(0.000361)\end{array}$ & & \\
\hline$M E G A P_{2}$ & & & $\begin{array}{c}0.00244 \\
(0.00216)\end{array}$ & $\begin{array}{l}-0.00124 \\
(0.00124)\end{array}$ \\
\hline $\mathrm{MEGAP}_{2}^{2}$ & & & $\begin{array}{c}-0.000163^{* *} \\
(7.30 \mathrm{e}-05)\end{array}$ & $\begin{array}{c}8.05 \mathrm{e}-06 \\
(5.86 \mathrm{e}-05)\end{array}$ \\
\hline SIZE & $\begin{array}{l}-1.150^{*} \\
(0.611)\end{array}$ & $\begin{array}{c}-1.358^{* * * *} \\
(0.375)\end{array}$ & $\begin{array}{c}-1.408 * * \\
(0.606)\end{array}$ & $\begin{array}{c}-1.547 * * * \\
(0.377)\end{array}$ \\
\hline DEBT & $\begin{array}{l}0.0523 * * \\
(0.0250)\end{array}$ & $\begin{array}{l}-0.00125 \\
(0.0117)\end{array}$ & $\begin{array}{l}0.0429^{*} \\
(0.0246)\end{array}$ & $\begin{array}{c}0.000204 \\
(0.0118)\end{array}$ \\
\hline AGE & $\begin{array}{l}0.000612 \\
(0.00150)\end{array}$ & $\begin{array}{l}0.00194 * * \\
(0.000964)\end{array}$ & $\begin{array}{l}0.000127 \\
(0.00151)\end{array}$ & $\begin{array}{c}0.00123 \\
(0.000972)\end{array}$ \\
\hline FROA & $\begin{array}{c}0.201 * * * \\
(0.0637)\end{array}$ & $\begin{array}{c}0.158 * * * \\
(0.0279)\end{array}$ & $\begin{array}{c}0.168 * * * \\
(0.0616)\end{array}$ & $\begin{array}{c}0.149 * * * \\
(0.0281)\end{array}$ \\
\hline Constant & $\begin{array}{c}0.182 \\
(0.144)\end{array}$ & $\begin{array}{c}0.288 * * * \\
(0.0844)\end{array}$ & $\begin{array}{c}0.322 * * * \\
(0.117)\end{array}$ & $\begin{array}{c}0.375 * * * \\
(0.0746)\end{array}$ \\
\hline Sample size & 465 & 1,452 & 465 & 1,452 \\
\hline$R^{2}$ & 0.060 & 0.074 & 0.078 & 0.058 \\
\hline Number of code & 112 & 373 & 112 & 373 \\
\hline
\end{tabular}

Note: Standard error in parentheses $* * * \mathrm{p}<0.01, * * \mathrm{p}<0.05, * \mathrm{p}<0.1$ 
The above table shows the relationship between pay gap and firm performance of different property rights. It can be seen that in the absolute pay gap model, the secondary term coefficient of private enterprises and state-owned enterprises are all negative and passing the significance test at the level of $1 \%$ and $10 \%$ respectively, indicating that the absolute salary gap and corporate performance have a significant inverted U-shaped relationship in private enterprises and state-owned enterprises and the turning point of state-owned enterprise precedes that of the private enterprise, verifying the hypothesis $\mathrm{H}_{2}$.

\section{Conclusion and suggestion}

In the high-tech industry listed companies, the pay gap between executives and ordinary employees and the next year company performance has inverted U-shaped relationship. Within a certain range, the tournament theory plays a leading role. The greater the pay gap between executives and ordinary employees, the better the company performance. Above the range, the behavior theory plays a leading role. As pay gap between executives and general employees increases, it is not conducive to the improvement of corporate performance.

The nature of property right in high-tech industry listed company has a moderating effect on the relationship between pay gap and corporate performance. The results of this study show that as the absolute pay gap increases, both state-owned enterprises and private enterprises have shown an inverted U-shaped curve, while the state-owned enterprises 's turning point precedes that of the private enterprises. In other words, state-owned enterprises are more suitable for relatively small pay gap. This conclusion reminds enterprises with different property right to consider their own corporate culture when formulating the salary incentive system and carefully adjusting the pay gap.

\section{References}

[1] Levine D I. Cohesiveness, productivity, and wage dispersion[J]. Institute for Research on Labor \& Employment Working Paper, 1991, 15(15):237-255.

[2] Milgrom P, Roberts J. An Economic Approach to Influence Activities in Organizations[J]. American Journal of Sociology, 1988, 94(Volume 94Number).

[3] Tao Y L, Chuang H L, Lin E S. Compensation and performance in Major League Baseball: Evidence from salary dispersion and team performance[J]. International Review of Economics \& Finance, 2016, 43:151-159.

[4] Zheng tang Zhang. Top management team collaboration needs, pay gaps and corporate performance: a perspective of competition theory [J]. Nankai Management Review, 2007, 10(2):4-11.

[5]Ye Liu, Dong xue Pei, Wei nan Liu. Empirical Research on Salary Gap, Governance Structure and High-tech Company Performance-Comparative Analysis with American High-Tech Companies [J]. Industrial Engineering and Management, 2014, 19(5):82-89.

[6]Yi Liao, Yi ming $\mathrm{Hu}$, Dong liang Fu. Internal pay gap, fair perception and employee productivity [J]. Investment research, 2016(3):43-57.

[7] Lazear E P, Rosen S. Rank-Order Tournaments as Optimum Labor Contracts.[J]. Social Science Electronic Publishing, 1979, 89(5):841-864.

[8] Harder J W. Play for Pay: Effects of Inequity in a Pay-for-Performance Context[J]. Administrative Science Quarterly, 1992, 37(2):321-335.

[9] Milkovich, George T. Compensation / 11th ed[M]. China Renmin University Press, 2014.

[10] Kale J R, Reis E, Venkateswaran A. Rank-Order Tournaments and Incentive Alignment: The Effect on Firm Performance[J]. Journal of Finance, 2009, 64(3):1479-1512. 
[11] Ming Zhang, Zhen Chen. An Empirical Study on the Implicit Incentives of Executive salary[J]. Financial research, 2006, 32(3):56-63.

[12] Jing Zhao Yang, Dong Tao Yang, Ya dong Cao. Pay gap and pay secrecy: based on cultural traditions [J]. Soft science, 2008, 22(5):39-45.

[13] Hui Cao. Executives-Employee Compensation Gap and Corporate Performance: An Empirical Study Based on Behavioral Perspective [J]. Friends of Accounting, 2014(26):62-66.

[14] Bingley P, Eriksson T. Pay Spread and Skewness, Employee Effort and Firm Productivity[J]. General Information, 2001.

[15] Dai Y, Kong D, Xu J. Does Fairness Breed Efficiency? Pay Gap and Firm Productivity in China [J]. International Review of Economics \& Finance, 2017, 48.

[16] Wenjing Li, Yu ming Hu. Who is motivated by the internal salary gap of state-owned enterprises? [J]. Economic Research, 2012(12):125-136.

[17] Liang mou Gao, Jian ci Lu. Research on the Asymmetric Incentive Effect of Internal Pay Gap-Based on the Threshold Panel Model of Manufacturing Enterprise Data [J]. Chinese industrial economy, 2015(8):114-129.

[18] Peiwen Bai. Research on the Influence of Different Main Body Income Gap on the Performance of China's A-share Listed Companies [J]. International financial research, 2011(4):87-96.

[19] Liu hong Shi, Shi miao Zhang, Zhao zhen Feng. Research on the Relationship between Salary Gap and Corporate Performance of Listed Companies Based on Panel Data [J]. Contemporary economic science, 2013, 35(4):64-73.

[20] Jun qing Lin, Zu hui Huang, Yong xiang Sun. Compensation gap, company performance and governance structure within the executive team [J]. Economic Research ,2003(4):31-4. 